\title{
Pola Infeksi pada Leukemia Mieloblastik Akut pada Anak
}

\author{
Hikari Ambara Sjakti, Endang Windiastuti \\ Departemen Ilmu Kesehatan Anak Fakultas Kedokteran Universitas Indonesia/RS. Dr. Cipto \\ Mangunkusumo, Jakarta
}

Latar belakang. Leukemia mieloblastik akut cenderung memiliki risiko terkena infeksi yang lebih tinggi dibandingkan keganasan lainnya. Angka kematian pada pasien LMA di Departemen Ilmu Kesehatan Anak FKUI/RSCM cukup tinggi, dan sebagian besar disebabkan oleh infeksi atau sepsis.

Tujuan. Mengetahui gambaran infeksi yang terjadi pada pasien LMA di Departemen Ilmu Kesehatan Anak FKUI/RSCM.

Metode. Penelitian deskritifretrospektif dilakukan terhadap rekam medis pasien anak penderita LMA yang terdiagnosis antara Januari 2007-Desember 2010. Hanya pasien yang memiliki data biakan darah atau urin yang diikutsertakan pada pada penelitian ini. Data hasil biakan dan luaran pasien dikumpulkan dan dianalisis.

Hasil. Terdapat 93 pasien baru LMA yang terdiagnosis selama kurun waktu penelitian, namun hanya 37 pasien yang memiliki data biakan darah atau urin. Enam belas dari 39 biakan darah dan 26 dari 42 biakan urin tumbuh bakteri yang sebagian besar adalah bakteri Gram negatif. Tujuh belas dari 23 pasien yang meninggal pada penelitian ini disebabkan oleh sepsis. Angka kematian akibat sepsis ini cenderung lebih tinggi dibandingkan penelitian lain. Hal ini mungkin terkait dengan toksisitas kemoterapi dan fasilitas perawatan khusus pasien imunokompromais yang tidak memadai.

Kesimpulan. Penyebab kematian tersering pada pasien LMA adalah infeksi bakteri Gram negatif. Perawatan suportif yang baik akan menurunkan kejadian komplikasi infeksi pada psien LMA yang menjalani kemoterapi. Sari Pediatri 2012;13(6):426-30.

Kata kunci: leukemia mieloblastik akut, infeksi, sepsis, biakan, anak

Alamat korespondensi:

Dr. Hikari Ambara Sjakti, Sp.A(K). Divisi Hematologi-Onkologi Departemen Ilmu Kesehatan Anak, FKUI- RSCM, Jl. Diponegoro 71, Jakarta 10430. Telp. (021) 31901170, Fax.: 021-3914145.

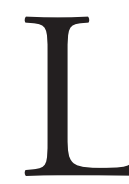

eukemia mieloblastik akut (LMA) merupakan keganasan yang cukup sering ditemukan pada anak. Di Departemen Ilmu Kesehatan Anak RS Dr. Cipto Mangunkusumo (IKA-RSCM) ditemukan 93 
anak selama tahun Januari 2007-Desember 2010. Kasus LMA ini mencapai $21,8 \%$ dari seluruh kasus keganasan pada anak atau menempati urutan kedua setelah leukemia limfoblastik akut. ${ }^{1}$ Pengobatan yang diberikan pada kasus LMA di Departemen IKA-RSCM adalah dengan kemoterapi memakai protokol yang diadopsi dari Emma Kinder Ziekenhuis/Academisch Medisch Centrum(EKZ/ AMC) 1987 yang bersumber dari protokol AMLBFM 87. Protokol ini kemudian dimodifikasi dengan mengurangi dosis Ara-C pada hari ke-5 sampai dengan hari ke- 8 dan tidak dilakukan transplantasi sumsum tulang (Tabel 1).

Hasil pengobatan LMA di negara-negara maju dalam beberapa dekade terakhir cenderung membaik yang ditunjukkan dengan angka remisi $70-90 \%,{ }^{2}$ dan probabilitas kesintasan yang meningkat dengan penggunaan transplantasi sumsum tulang. ${ }^{2}{ }^{3}$ Namun hasil pengobatan LMA di Dep. IKA-RSCM masih belum memuaskan karena tingginya angka kematian akibat komplikasi infeksi. Anak yang menderita leukemia mieloblastik akut (LMA) sangat rentan terhadap infeksi. ${ }^{4}$ Sebanyak 50 dari 93 pasien LMA yang diobati di Dep. IKA-RSCM meninggal dan $62 \%$ diantaranya meninggal akibat infeksi berat. ${ }^{1}$ Sejauh ini belum ada laporan komplikasi infeksi pada pasien LMA yang dipublikasikan oleh Departemen Ilmu Kesehatan Anak RSCM. Penelitian ini dilakukan untuk mengetahui profil infeksi pada pasien LMA di Departemen IKA-RSCM.

\section{Metode}

Penelitian ini adalah penelitian deskriptif retrospektif pada rekam medis. Semua pasien berusia kurang dari 18 tahun yang didiagnosis LMA antara Januari 2007 sampai dengan Desember 2010di Departemen IKA-RSCM dan memiliki data biakan darah atau urin diikutsertakan sebagai subyek penelitian ini. Diagnosis dan klasifikasi LMA ditegakkan berdasarkan gambaran morfologi dengan memakai French-American-British (FAB) classification.Protokol pengobatan LMA yang dipakai adalah protokol dari Emma Kinder Ziekenhuis/Academisch Medisch Centrum(EKZ/AMC) 1987 yang dimodifikasi, terdiri dari fase induksi, fase konsolidasi, 2 blok fase intensifikasi (Tabel 1). Transplantasi sumsum tulang tidak termasuk dalam protokol karena fasilitas tersebut belum tersedia.

Variabel yang dinilai adalah karakteristik klinis dan laboratoris, data infeksi, hasil biakan darah dan biakan urin dan luaran pengobatan.

\section{Hasil}

Sebanyak 93 pasien didiagnosis LMA selama waktu penelitian ini.Sebanyak dua pertiga pasien berusia antara 1-10 tahun saat didiagnosis. Tipe LMA terbanyak tipe M1 (50\%) kasus, disusul tipe M4 dan M2 (Tabel 2).

Tabel 1. Protokol kemoterapi LMA

\begin{tabular}{|c|c|}
\hline $\begin{array}{l}\text { Fase induksi } \\
\text { (1 blok) }\end{array}$ & $\begin{array}{l}\text { MTX+Ara-C IT h1 } \\
\text { Ara-C } 50 \mathrm{mg} / \mathrm{m}^{2} \text { infus } 24 \text { jam h1-2, Ara-C } 50 \mathrm{mg} / \mathrm{m}^{2} \text { bolus } / 12 \text { jam h3-4; } \\
\text { Ara-C } 75 \mathrm{mg} / \mathrm{m}^{2} \text { bolus } / 12 \text { jam h5-6; Ara-C } 100 \mathrm{mg} / \mathrm{m}^{2} \text { bolus } / 12 \text { jam h-7-8 } \\
\text { Dauborubisin } 30 \mathrm{mg} / \mathrm{m}^{2} \text { infus } / 12 \text { jam h3,4,5 } \\
\text { Etoposid } 150 \mathrm{mg} / \mathrm{m}^{2} \text { infus/hari h6,7,8 }\end{array}$ \\
\hline Fase konsolidasi & $\begin{array}{l}\text { Deksametason } 4 \mathrm{mg} / \mathrm{m}^{2} \text { po, h1-28 } \\
\text { 6-MP } 50 \mathrm{mg} / \mathrm{m}^{2} \text { po, h1-28 } \\
\text { Vinkristin } 1,5 \mathrm{mg} / \mathrm{m}^{2} \text { bolus, h1,8,15,22 } \\
\text { Adriamisin } 30 \mathrm{mg} / \mathrm{m}^{2} \text { bolus, h1,8,15,22 } \\
\text { Ara-C } 75 \mathrm{mg} / \mathrm{m}^{2} \text { bolus, h2-4, h9-12, h16-19, 23-26, h30-33, h37-40 } \\
\text { Siklofosfamid } 500 \mathrm{mg} / \mathrm{m}^{2} \text { infus h29,43 } \\
\text { MTX+Ara-C IT h1,15,29,43 }\end{array}$ \\
\hline $\begin{array}{l}\text { Fase intensifikasi } \\
\text { ( } 2 \text { blok) }\end{array}$ & $\begin{array}{l}\text { Ara-C } 3 \mathrm{~g} / \mathrm{m}^{2} \text { infus } / 12 \text { jam h } 1-3 \\
\text { Etoposid } 125 \mathrm{mg} / \mathrm{m}^{2} \text { infus } \mathrm{h} 2-5\end{array}$ \\
\hline
\end{tabular}


Hanya 37 dari 93 pasien yang memiliki data biakan darah atau urin. Alasan dilakukan pemeriksaan biakan darah dan urin adalah demam neutropenia atau pasien dicurigai mengalami infeksi saat perawatan di rumah sakit. Jumlah pemeriksaan biakan darah dan biakan urin total yang ditemukan pada penelitian ini masingmasing adalah 39 dan 42 biakan (Tabel 3).

Terdapat dua pasien dilakukan dua kali biakan darah. Seorang pasien menunjukkan hasil biakan steril pada pemeriksaan pertama dan Streptococcus anhemolyticus pada biakan darah kedua. Seorang pasien lainnya menunjukkan hasil biakan darah pertama Pseudomonas aeruginosa pada biakan pertama, dan Klebsiella pneumonia pada biakan darah kedua. Pada kedua pasien ini, kedua biakan darah dilakukan pada episode sakit atau demam neutropenia yang berbeda.

Dijumpai juga seorang pasien menjalani tiga kali pemeriksaan biakan urin dan ketiga-tiganya menunjukkan biakan urin positif, masing-masing Acinetobacter sp, Escherichia coli dan Candida. Ketiga biakan tersebut dilakukan pada episode sakit atau demam neutropenia yang berbeda. Juga terdapat duapasien yang menjalani dua kali pemeriksaaan biakan urin pada episode sakit yang berbeda. Seorang diantaranya menunjukkan hasil biakan urin Klebsiella pneumonia dan biakan keduanya steril, sedangkan seorang pasien lagi menunjukkan hasil biakan urin Staphylococcus saprophyticus dan biakan kedua steril.

Ditemukan 23 dari 39 biakan darah tidak tumbuh bakteri. Hasil biakan yang steril ditemukan lebih

Tabel 2. Karakteristik klinis dan laboratoris pasien LMA

\begin{tabular}{lc}
\hline Variabel & Frekuensi \\
\hline Jenis kelamin & \\
Laki-laki & 57 \\
Perempuan & 36 \\
Usia (tahun) & \\
0 -1 & 10 \\
$>1-10$ & 61 \\
>10 & 22 \\
Klasifikasi FAB & \\
M1 & 42 \\
M2 & 15 \\
M3 & 2 \\
M4 & 18 \\
M5 & 9 \\
M6 & 1 \\
M7 & 6 \\
\hline
\end{tabular}

sedikit pada biakan urin yaitu 16 dari 42 biakan. Umumnya bakteri yang tumbuh adalah bakteri Gram negatif, 14 dari 16 biakan darah yang positif adalah bakteri Gram negatif, dan pada biakan urin 19 dari 26 biakan adalah bakteri Gram negatif. Bakteri terbanyak yang ditemukan pada biakan darah adalah Pseudomonas aeruginosa, sedangkan pada biakan urin adalah Acinetobacter calcoaceticus (Tabel 3).

Tabel 3. Hasil biakan darah dan urin

\begin{tabular}{|c|c|}
\hline Variabel & $\mathrm{n}$ \\
\hline Biakan darah (dari 37 pasien) & 39 \\
\hline Steril & 23 \\
\hline Tumbuh & 16 \\
\hline Gram negatif & 14 \\
\hline Pseudomonas aeruginosa & 5 \\
\hline Acinetobacter sp & 3 \\
\hline Klebsiella pneumonia & 3 \\
\hline Klebsiella ozaenae & 1 \\
\hline Aerobacter aerogenes & 1 \\
\hline Serratia liquefaciens & 1 \\
\hline Gram positif & 2 \\
\hline Streptococcus epidermidis & 1 \\
\hline Streptococcus anhemolyticus & 1 \\
\hline Biakan urin (dari 37 pasien) & 42 \\
\hline Steril & 16 \\
\hline Tumbuh & 26 \\
\hline Gram negatif & 19 \\
\hline Acinetobacter calcoaceticus & 8 \\
\hline E. coli & 3 \\
\hline Klebsiella pneumonia & 3 \\
\hline Pseudomonas aeruginosa & 3 \\
\hline Proteus mirabilis & 1 \\
\hline Serratia sp & 1 \\
\hline Gram positif & 6 \\
\hline Streptococcus anhemolyticus & 3 \\
\hline Staphylococcus saprophyticus & 2 \\
\hline Staphylococcus epidermidis & 1 \\
\hline Jamur (Candida) & 1 \\
\hline
\end{tabular}

Tabel 4.Penyebab kematian dan hasil biakan

\begin{tabular}{lc}
\hline Variabel & Jumlah \\
\hline Meninggal & 50 dari 93 pasien \\
- Bukan akibat infeksi & 19 \\
- Akibat infeksi & 31 \\
Pasien meninggal dan menjalani biakan & 23 \\
- Biakan tumbuh (Gram positif) & 2 \\
- Biakan tumbuh (Gram negatif) & 13 \\
- Biakan steril & 2 \\
\hline
\end{tabular}


Luaran pengobatan LMA penelitian ini menunjukkan angka kematian yang tinggi yaitu 50 dari 93 pasien atau $53,8 \%$. Kematian pada fase induksi yang erat kaitannya dengan infeksi merupakan yang tertinggi yaitu 38\% dari seluruh kematian. Penyebab utama kematian adalah infeksi berat atau sepsis (62\%) dan sisanya akibat perdarahan atau penyebab lain. Sebanyak 23 dari 37 pasien yang menjalani biakan darah dan urin meninggal, dan 17 diantaranya meninggal akibat infeksi atau sepsis (Tabel 4). Dari 17 pasien yang meninggal akibat sepsis tersebut, 2 pasien memiliki hasil biakan darah dan urin steril, sedangkan sisanya terbukti adanya bakteri pada biakan darah atau urin.

\section{Pembahasan}

Protokol kemoterapi yang digunakan pada penelitian kami mengacu pada protokol kemoterapi EKZ/AMC87 yang didasarkan pada protokol BFM-AML 87. Protokol ini merupakan protokol LMA yang sangat intensif dan sangat toksik. ${ }^{5}$ Angka kematian yang cukup tinggi pada penelitian ini mungkin berkaitan dengan tingginya kejadian infeksi berat (sepsis) akibat komplikasi kemoterapi. Meskipunangka kematian pada penelitian ini masih lebih tinggi dari yang dilaporkan oleh penelitian lain yang menggunakan protokol kemoterapi yang hampir sama. Ribeiro $\mathrm{dkk}^{5}$ melaporkan angka kematian akibat komplikasi infeksi pada pasien yang mendapat protokol fase induksi BFM-AML 87dan ditunjang fasilitas perawatan yang optimal hanya sebanyak $15 \%$. Perbedaan angka kematian yang besar dengan penelitian ini mungkin disebabkan oleh tidak adanya sarana perawatan yang memadai untuk pasien imunokompromais dan sedang menjalani kemoterapi. ${ }^{6}$ Pasien LMA yang mendapat kemoterapi pada penelitian ini umumnya dirawat di ruang rawat biasa sehingga sangat rentan terkena infeksi. Ruang rawat isolasi yang ada tidak memadai dan sangat kurang jumlahnya.

Laporan mengenai bakteri penyebab infeksi pada pasien keganasan cenderung bervariasi. Sebagian besar bakteri yang terdeteksi pada penelitian ini adalah bakteri Gram negatif, serupa seperti laporan Yilmaz $\mathrm{dkk}^{7}$ yang melaporkan $61,8 \%$ pasien leukemia yang mengalami demam neutropenia terbukti terinfeksi bakteri Gram negatif. Infeksi tersebut secara bermakna terkait dengan makin lamanya demam neutropenia dan makin rendahnya jumlah neutrofil absolut. Namun laporan Aledo $\mathrm{dkk}^{6}$ melaporkan hasil yang berbeda dari penelitian ini. Penelitiannya pada pasien keganasan yang mengalami syok septik menemukan bukti infeksi Gram positif lebih banyak ditemukan (46,5\%) dibandingkan bakteri Gram negatif (40,6\%). Tezcan $\mathrm{dkk}^{8}$ juga melaporkan hasil serupa seperti Aledo dkk pada lebih dari 400 pasien anak dengan diagnosis keganasan dan demam neutropenia. Perbedaan jenis infeksi bakteri ini mungkin terkait dengan fokus infeksi yang diderita pasien, Tezcan dkk lebih banyak menemukan infeksi saluran nafas pada pasien yang ditelitinya.

Penyebab kematian terbanyak pada penelitian kami adalah infeksi atau sepsis (62\%). Hal serupa dilaporkan oleh Riley dkk ${ }^{9}$ dari Medical Research Council (MRC) United Kingdom bahwa kematian pasien LMA yang memakai protokol MRC 10 mencapai $13,8 \%$ dan $65,9 \%$ diantaranya disebabkan oleh infeksi. Gibson $\mathrm{dkk}^{10}$ yang melanjutkan penelitian tersebut dengan protokol yang direvisi dan toksisitasnya lebih rendah (MRC 12) mendapatkan angka kematian akibat infeksi yang lebih rendah. Molgaard-Hansen $\mathrm{dkk}^{11}$ tahun 2011 juga melaporkan penyebab tersering kematian pada pasien LMA anak yang ditelitinya adalah infeksi, yaitu sebanyak 59\%.Demikian pula Chan $\mathrm{dkk}^{12}$ di Malaysia yang memakai protokol kemoterapi AML 83 yang kurang toksik melaporkan 52\% penyebab kematian pasien LMA adalah sepsis.

Angka kematian yang tinggi akibat sepsis pada pasien LMA seperti halnya pada penelitian ini dan penelitian-penelitian lainnya sesuai dengan laporan Basu dkk ${ }^{13}$ bahwa sepsis pada LMA berkorelasi dengan 10 kali risiko kematian dibandingkan pasien keganasan bukan LMA. Masalah toksisitas obat dan perawatan suportif merupakan faktor yang diduga berkaitan dengan hal ini. ${ }^{11,12,14}$ Selain itu, angka kematian akibat sepsis pada penelitian ini mungkin juga berkaitan dengan tingginya persentase infeksi bakteri Gram negatif. Aledo $\mathrm{dkk}^{6}$ melaporkan bahwa infeksi Gram negatif pada pasien keganasan yang mengalami demam neutropenia merupakan faktor risiko terjadi syok septik dan kematian.

\section{Kesimpulan}

Infeksi bakteri Gram negatif merupakan penyebab infeksi tersering pada pasien LMA dan berkaitan dengan tingginya angka kematian. Perawatan suportif yang baik dan sarana perawatan yang memadai mutlak diperlukan 
untuk mengurangi komplikasi infeksi pada pasien LMA yang menjalani pengobatan kemoterapi.

\section{Daftar pustaka}

1. Data Registrasi Kanker Departemen Ilmu Kesehatan Anak FKUI/RSCM 2011.

2. Creutzig U, Ritter J, Schellong G. Identification of two risk groups in childhood acute myelogenous leukemia after therapy intensification in study AML-BFM-83 as compared with study AML-BFM-78. AML-BFM Study Group. Blood. 1990;75:1932-40.

3. Klingebiel T, Creutzig U, Dopfer R, Ehninger G, Schmidt H, Ritter J, dkk. Bone marrow transplantation in comparison with conventional therapy in children with adult type chronic myelogenous leukemia. Bone Marrow Transplant. 1990;5:317-20.

4. Feusner JH, Hastings CA. Infections in children with acute myelogenous leukemia. Concepts of management and prevention. J Pediatr Hematol Oncol. 1995;17:234-47.

5. Ribeiro RC, Razzouk BI, Pounds S, Hijiya N, Pui CH, Rubnitz JE. Successive clinical trials for childhood acute myeloid leukemia at St Jude Children's Research Hospital, from 1980 to 2000. Leukemia. 2005;19:2125-9.

6. Aledo A, Heller G, Ren L, Gardner S, Dunkel I, McKay SW, dkk. Septicemia and septic shock in pediatric patients: 140 consecutive cases on a pediatric hematology-oncology service. J Pediatr Hematol Oncol. 1998;20:215-21.

7. Yilmaz S, Oren H, Demircioglu F, Irken G. Assessment of febrile neutropenia episodes in children with acute leukemia treated with BFM protocols. Pediatr Hematol Oncol. 2008;25:195-204.
8. Tezcan G, Kupesiz A, Ozturk F, Ogunc D, Gultekin M, Yesilipek A, dkk. Episodes of fever and neutropenia in children with cancer in a tertiary care medical center in Turkey. Pediatr Hematol Oncol. 2006;23:217-29.

9. Riley LC, Hann IM, Wheatley K, Stevens RF. Treatment-related deaths during induction and first remission of acute myeloid leukaemia in children treated on the Tenth Medical Research Council acute myeloid leukaemia trial (MRC AML10). The MCR Childhood Leukaemia Working Party. Br J Haematol. 1999; 106:436-44.

10. Gibson BE, Wheatley K, Hann IM, Stevens RF, Webb D, Hills RK, dkk. Treatment strategy and long-term results in paediatric patients treated in consecutive UK AML trials. Leukemia. 2005;19:2130-8.

11. Molgaard-Hansen L, Mottonen M, Glosli H, Jonmundsson GK, Abrahamsson J, Hasle H. Treatment-related deaths in second complete remission in childhood acute myeloid leukaemia. Br J Haematol. 2011;15:623-30.

12. Chan LL, Abdel-Latif ME, Ariffin WA, Ariffin H, Lin HP. Treating childhood acute myeloid leukaemia with the AML-BFM-83 protocol: experience in a developing country. Br J Haematol. 2004;126:799805.

13. Basu SK, Fernandez ID, Fisher SG, Asselin BL, Lyman GH. Length of stay and mortality associated with febrile neutropenia among children with cancer. J Clin Oncol. 2005;23:7958-66.

14. Creutzig U, Zimmermann M, Reinhardt D, Dworzak M, Stary J, Lehrnbecher T. Early deaths and treatmentrelated mortality in children undergoing therapy for acute myeloid leukemia: analysis of the multicenter clinical trials AML-BFM 93 and AML-BFM 98. J Clin Oncol. 2004;22:4384-93. 